\title{
Correction
}

\section{Correction: Temperature and Photoperiod Interactions with Phosphorus-Limited Growth and Competition of Two Diatoms}

\section{The PLOS ONE Staff}

There is an error in the citation for Equation 5. The citation is: Fuhs [49].

In Table 1, the parameters for dilution factor and time are incorrect. The parameter for dilution factor should be " $f$ ", and the parameter for time should be "t". Please see the corrected Table 1 here.

Table 1. Model parameters and variables for simulation of P-competition and relative uptake rates in semi-continuous culture experiments.

\begin{tabular}{|c|c|c|}
\hline Parameter & Meaning & Units \\
\hline $\mathrm{x}$ & Biovolume & $\mathrm{mm}^{3} \mathrm{~L}^{-1}$ \\
\hline Q & P-quota & $\mu \mathrm{g} P \mathrm{~mm}^{-3}$ \\
\hline $\mathrm{S}_{\mathrm{m}}$ & Concentration of $\mathrm{P}$ in fresh medium & $\mu g \mathrm{P} \mathrm{L}^{-1}$ \\
\hline $\mathrm{V}_{\text {rel, } \mathrm{i}}$ & Biovolume-specific proportion of $\mathrm{P}$ absorbed by species $\mathrm{i}$ & Dimensionless \\
\hline$\mu$ & Specific growth rate, given by Eq. 5 with the parameters in Table 3 . & $d^{-1}$ \\
\hline$f$ & Dilution factor (proportion of culture retained at dilution) & Dimensionless \\
\hline $\mathrm{t}$ & Time & $d$ \\
\hline$\Delta \mathrm{t}$ & Time until next dilution & $d$ \\
\hline D & Dilution rate & $d^{-1}$ \\
\hline
\end{tabular}

Subscripts $i$ and $j$ refer to the two species.

doi:10.1371/journal.pone.0102367.t001

\section{Reference}

1. Shatwell T, Köhler J, Nicklisch A (2014) Temperature and Photoperiod Interactions with Phosphorus-Limited Growth and Competition of Two Diatoms. PLoS ONE 9(7): e102367. doi:10.1371/journal.pone.0102367 